\title{
Evaluating the Effectiveness of Mitigation Options on Heat Stress for Sydney, Australia $\mathscr{A}$
}

\author{
SHAOXIU MA AND ANDY PITMAN \\ Australian Research Council Centre of Excellence for Climate System Science, Climate Change Research Centre, \\ University of New South Wales, Sydney, New South Wales, Australia \\ JIACHUAN YANG \\ School of Sustainable Engineering and the Built Environment, Arizona State University, Tempe, Arizona \\ Claire Carouge, Jason P. Evans, Melissa Hart, and Donna Green \\ Australian Research Council Centre of Excellence for Climate System Science, Climate Change Research Centre, \\ University of New South Wales, Sydney, New South Wales, Australia
}

(Manuscript received 11 March 2017, in final form 7 October 2017)

\begin{abstract}
Global warming, in combination with the urban heat island effect, is increasing the temperature in cities. These changes increase the risk of heat stress for millions of city dwellers. Given the large populations at risk, a variety of mitigation strategies have been proposed to cool cities-including strategies that aim to reduce the ambient air temperature. This paper uses common heat stress metrics to evaluate the performance of several urban heat island mitigation strategies. The authors found that cooling via reducing net radiation or increasing irrigated vegetation in parks or on green roofs did reduce ambient air temperature. However, a lower air temperature did not necessarily lead to less heat stress because both temperature and humidity are important factors in determining human thermal comfort. Specifically, cooling the surface via evaporation through the use of irrigation increased humidity-consequently, the net impact on human comfort of any cooling was negligible. This result suggests that urban cooling strategies must aim to reduce ambient air temperatures without increasing humidity, for example via the deployment of solar panels over roofs or via cool roofs utilizing high albedos, in order to combat human heat stress in the urban environment.
\end{abstract}

\section{Introduction}

Human heat stress is a complex measure combining temperature, humidity, wind speed, and radiant heat, coupled with individual factors including age, metabolism, physical activity, and health (Willett and Sherwood 2012). Humans experience a direct physiological vulnerability to heat stress (Guo et al. 2016; Shi et al. 2015). In addition, societies experience indirect vulnerabilities to heat stress such as impacts of heat on economic productivity (Dunne et al. 2013; Zander et al. 2015). The risk of heat stress on

\footnotetext{
Supplemental information related to this paper is available at the Journals Online website: https://doi.org/10.1175/JAMC-D-170061.s1.
}

Corresponding author: Prof. Andrew Pitman, a.pitman@unsw. edu.au urban residents is increasing in some regions because of urbanization, the urban heat island (UHI) effect (Fischer et al. 2012; Oleson et al. 2015), and global warming (Sherwood and Huber 2010; Zhao et al. 2015). While it is possible that some cities are seeing a decline in heatrelated mortality (Barnett 2007; Carson et al. 2006; Davis et al. 2003; Sheridan et al. 2009), the overall trend is toward increasing heat stress on humans. Some of these trends are already significant and projected to be of increasing concern for planners in the short and medium term. Indeed, heat-related events are the principal cause of death from natural disasters in the United States (Buzan et al. 2015). However, while temperature trends and temperature variability are important (e.g., Guo et al. 2016), any increase in humidity would also affect human health and comfort by reducing how effectively our bodies cool (Willett and Sherwood 2012; Zhao et al. 2015). It is therefore necessary to account for variations in both 
temperature and humidity in estimating how future climate, urbanization, and temperature mitigation options affect outcomes ranging across sectors including human health and economic outcomes.

Multiple mitigation strategies have been proposed to reduce urban temperatures. Specific suggestions include green roofs, cool roofs, roof solar panel deployment, and urban irrigation. Green roofs reduce 2-m urban air temperatures by increasing evaporative cooling and decreasing sensible heat exchange (Sun et al. 2016; Vijayaraghavan 2016). Cool roofs (light-colored or white roofs) reduce 2-m urban temperatures by increasing the reflection of incoming solar radiation $(\mathrm{Li}$ et al. 2014; Yang et al. 2015b). In combination, green roofs and cool roofs can reduce 2-m ambient air temperatures by $3^{\circ}-4^{\circ} \mathrm{C}$ depending on the building characteristics, urban environment, and meteorological and geographical conditions. For example, Li et al. (2014) showed that green roofs with relatively abundant moisture cooled 2-m ambient air temperatures by up to $3.5^{\circ} \mathrm{C}$ over the Baltimore, Maryland-Washington, D.C., metropolitan area, and a cool roof with an albedo value of 0.7 reduced $2-\mathrm{m}$ temperatures by $3^{\circ} \mathrm{C}$. Sharma et al. (2016) also found a green roof in metropolitan Chicago, Illinois, reduced 2-m ambient air temperature but by less than $1^{\circ} \mathrm{C}$, and a cool roof with an albedo of 0.85 had a slightly stronger cooling effect than the green roof. The success of various mitigation strategies can be city and climate dependent. For example, cool roofs were more successful in reducing 2-m ambient temperature for cities in dry regions than in humid regions across the contiguous United States (Georgescu et al. 2014). Installing solar panels over roofs-or using solar tiles as roofing material—could also reduce ambient air temperature. Solar panels absorb solar radiation and convert it to electricity (Masson et al. 2014; Salamanca et al. 2016; Taha 2013). This reduces the energy available for sensible heat exchange that would otherwise warm the atmosphere (Hu et al. 2016) and has the added economic benefit of localized electricity generation. Alternative methods, including irrigation of green roofs and/or parks, can also help reduce ambient air temperatures (Tsilini et al. 2015; Van Mechelen et al. 2015; Yang and Wang 2015) by increasing the latent heat flux and, through energy balance constraints, reducing sensible heat exchange.

While many previous studies have investigated how to cool urban areas, few have compared the effectiveness of different cooling strategies on heat stress or human comfort. A lower air temperature by itself does not necessarily lead to less heat stress because humidity is also an important factor in determining human thermal comfort. Ohashi et al. (2016) and Sun et al. (2016), for example, explored the mechanisms of how cool roofs and green roofs mitigated heat stress using single heat stress indices. Building on these studies, we compare the effectiveness of cool roofs, green roofs, deployment of solar panels, and irrigation practices on human heat stress for Sydney, Australia. We perform this analysis through the use of newly available green roof model and irrigation practices implemented in a coupled regionalscale atmosphere-urban modeling system. We employ three different heat stress indices and account for temperature and humidity as a first step toward future studies that could account simultaneously for temperature, humidity, radiation, and wind.

\section{Methods and experimental design}

Sydney is located on the Australian east coast and extends approximately $100 \mathrm{~km}$ north-south and $100 \mathrm{~km}$ inland. The climate of Sydney is humid subtropical, shifting from mild and cool in the winter to warm and hot in the summer. Seasonal differences are relatively small because of the proximity of the ocean. The maximum and minimum temperatures in summer are $\sim 27^{\circ}$ and $\sim 19^{\circ} \mathrm{C}$, respectively. Annual rainfall is $\sim 1200 \mathrm{~mm}$ with highest rainfall typically in February and June (Australian Bureau of Meteorology 2017).

\section{a. WRF-urban modeling system}

We used the Weather Research and Forecasting (WRF) Model, version 3.7.1 (Skamarock et al. 2008), coupled with a single-layer urban canopy model (SLUCM; Chen et al. 2011; Kusaka et al. 2001; Kusaka and Kimura 2004) as the numerical tool to simulate the urban climate. The SLUCM represents the urban landscape as buildings of equal height on two sides of the infinitely long street canyons, with various urban surfaces (roofs, walls, and roads) to introduce different sensible heat fluxes. The effects of shadowing, reflection, and trapping of radiation in the street canyon are considered. Performance of the WRF-SLUCM has been extensively validated over global metropolitan areas (e.g., Chen et al. 2011; Miao and Chen 2014).

The physics schemes and urban parameters used here have been evaluated over Australia (Argüeso et al. 2014, 2015; Evans et al. 2014) and the Sydney region (Argüeso et al. 2014). This configuration uses the WRF singlemoment 5-class microphysics scheme, the Rapid Radiative Transfer Model (RRTM) longwave radiation scheme, the Dudhia shortwave radiation scheme, the MoninObukhov surface-layer similarity, the Noah land surface scheme, the Yonsei University boundary layer scheme, and the Kain-Fritsch cumulus physics scheme. No cumulus physics is used for the 2-km-resolution simulation because most convection can be explicitly resolved. 
We run six experiments plus one control simulation in two groups. The first group compares the effectiveness of the cool roofs (COOL), roofs with solar panels (SD60), and green roofs (GR).

\section{1) $\mathrm{COOL}$}

Cool roofs reduce the overall net radiation available at the roof surface by reflecting shortwave radiation because of a higher surface albedo. The albedo of cool roofs used in previous studies ranges from 0.35 to 0.9 (Oleson et al. 2010; Sharma et al. 2016; Yang et al. 2015b). We used a median value of albedo [0.64, increased by 0.44 relative to default roof surface albedo (0.2)], which has an impact on the available energy for the surface energy balance that is comparable to that of our solar panel experiment.

\section{2) SD60}

Conventional photovoltaic (PV) panels are undergoing rapid technological development and are becoming more energy efficient (Hu et al. 2016); concentrated PV (CPV) panels are projected to achieve a $60 \%$ efficiency in the next few years (Green et al. 2016). We therefore examined the utility of $60 \%$ efficiency as the potential mitigation capacity. We assumed that the albedo of the solar panel is 0.1 (Hu et al. 2016), where the albedo of the urban surface is 0.2 . The $60 \%$ efficiency indicates that $60 \%$ of the remaining direct shortwave radiation $(90 \%)$ after reflection was absorbed by the panels and converted to electricity.

\section{3) GR}

The green roof model, incorporating an advanced hydrology model, was implemented in SLUCM and validated against observations (Yang et al. 2015a, 2016; Yang and Wang 2014). Green roofs have a four-layer structure with a total depth of $50 \mathrm{~cm}$ including a $15-\mathrm{cm}$ loam soil (top two layers for vegetation), $15-\mathrm{cm}$ growing layer, drainage layer, and $20-\mathrm{cm}$ concrete roof layer. Thermal and hydrological parameters for the green roof algorithm are discussed in Yang and Wang (2014).

In the second group of experiments, irrigation was implemented for green roofs (experiment GR+IRI); gardens and parks (experiment GD+IRI); and in combination with irrigation implemented for all green roofs, gardens, and parks (experiment GR $+\mathrm{GD}+\mathrm{IRI}$ ). The WRF green roof model uses a dynamic irrigation algorithm for summer months from 2100 to 2200 local standard time (LST) to enhance soil moisture to field capacity for the top two layers $(15 \mathrm{~cm})$. The same irrigation scheme is applied to the top two soil layers $(10+$ $30 \mathrm{~cm}$ ) of the urban ground vegetation. Urban irrigation often happens at nighttime to avoid rapid moisture loss caused by high temperatures in daytime (Yang and Wang 2015). Sensitivity analysis (not shown here) found that changing the irrigation time (1-h period shifting from 2000 to 0400 LST) had a negligible impact on mean nighttime and daytime temperature, because evaporation was very small at night as a result of low available energy at the surface. We assumed the coverage of COOL, GR, and SD60 on roofs is $100 \%$ as we aim to explore the potential mitigation capacity. This potential capacity of mitigation by COOL, GR, and SD60 can be used to estimate the impact of lower-scale implementations because the relationship between the impact on temperature, humidity, and heat stress indices are generally linear (Sharma et al. 2016; Sun et al. 2016; Ma et al. 2017a). The daily constant irrigation scheme used here results in the use of approximately $150 \mathrm{~mm}$ of water per summer month. The daily constant irrigation, at such a significant rate, is obviously rather extreme, but we wanted to examine the potential mitigating impact of irrigation in the same sense as we examined the potential impact of cool roofs or largescale implementation of solar panels. All experiments were run for January (summer) 2007, 2008, and 2009 over Sydney. Hourly data were saved for analysis, and the first 3 days were discarded as a spinup period. We show the ensemble mean of the three summer months in subsequent analysis.

\section{b. Model setup and experiments}

The WRF-SLUCM is used with one-way nesting and three domains with a 50-, 10-, and 2-km resolution (Fig. 1a). Each mitigation strategy was examined separately. The WRF-SLUCM was initialized and updated at the lateral boundaries using the ERA-Interim at 6-h intervals (Dee et al. 2011). Urban land use is classified into high- $(57 \%$ roof space, $38 \%$ roads, and $5 \%$ vegetation and bare soil), medium- (45\% roof space, $45 \%$ roads, and $10 \%$ vegetation and bare soil), and low ( $25 \%$ roof space, $25 \%$ roads, and $50 \%$ vegetation and bare soil)-intensity development (Figs. $1 \mathrm{~b}$ and 1c). This landuse dataset category was derived from multiple sources, including the default WRF land use, the land-use map of the New South Wales Office of Environment and Heritage (urban-OEH) as used by Argüeso et al. (2014), and the urban land-use intensity map that classifies the urban areas into four types (low, medium, high, and tall buildings, which was merged into the high intensity as defined in WRF-SLUCM) according to population density (Jackson et al. 2010). A detailed description of the method used to combine the three datasets is available in Ma et al. (2017b).

\section{c. Heat stress metrics}

Many heat stress indices have been proposed to combine different environmental variables, including temperature, humidity, wind speed, and radiation (Buzan et al. 2015; 

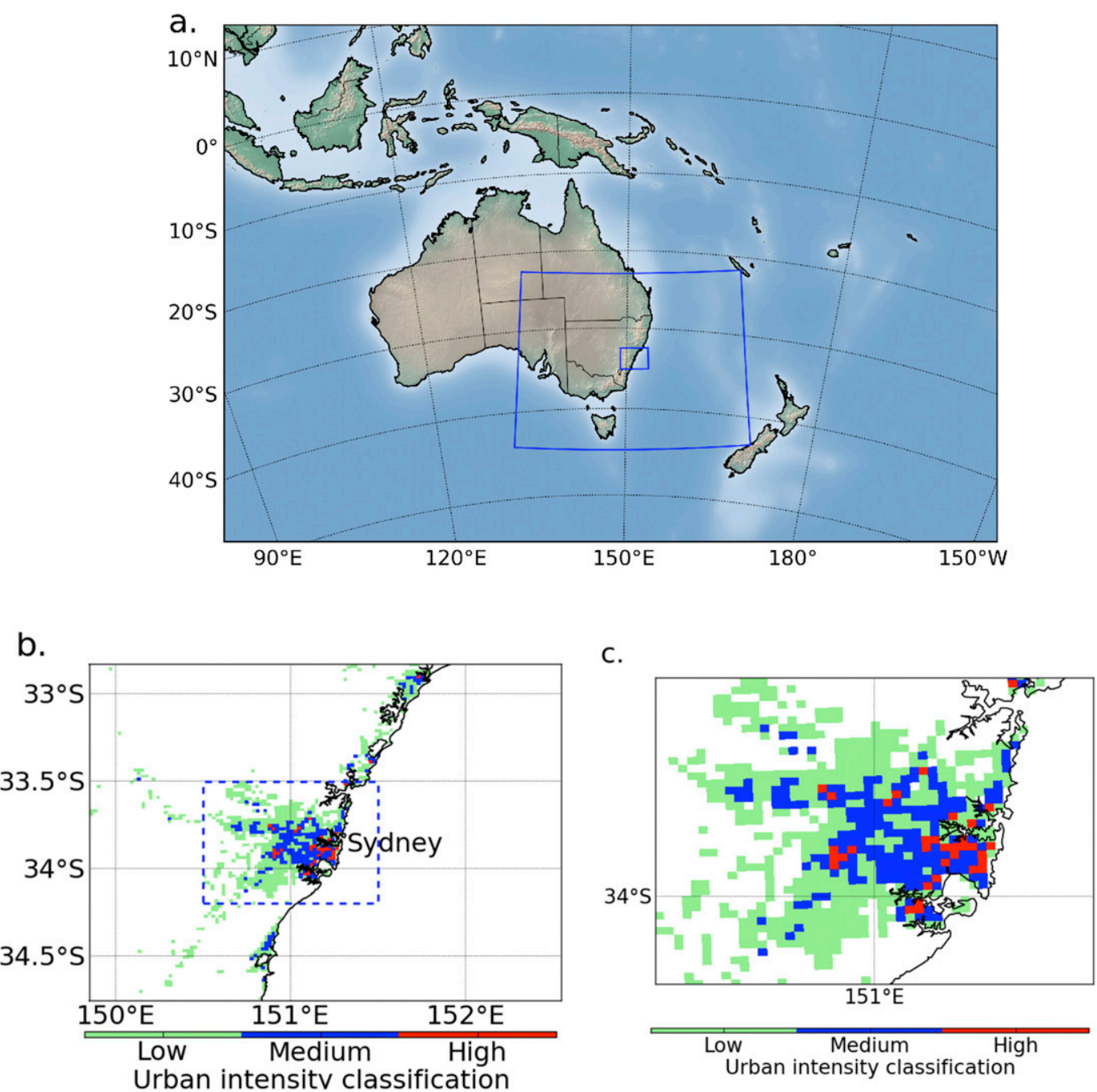

FIG. 1. The domains, along with the density of the urban surface used by WRF. (a) The large-scale domain, resolved at $50 \mathrm{~km}$; the large and small blue-outlined rectangles show the regions modeled at 10 and $2 \mathrm{~km}$, respectively. (b) The 2-kmresolution domain, showing regions of low-, medium-, and high-density urban land cover. (c) A blow-up of the dashoutlined area in (b), which is also the region used for diagnostic and illustrative purposes in Figs. 2, 3, and 4, below.

Hass et al. 2016). However, most commonly, temperature and humidity are used to define heat stress (Buzan et al. 2015; Hass et al. 2016; Oleson et al. 2015; Zhao et al. 2015). There is no single agreed heat stress metric; some metrics have a strong dependency on moisture, while others have a strong dependency on temperature (Buzan et al. 2015). We avoid making an a priori decision on the "best" heat stress index, and instead, we use three indices widely used both globally and particularly in Australia. These three indices are the simplified wet-bulb globe temperature (SWBGT), apparent temperature (AT), and humidity index (humidex). Since SWBGT has been quite commonly used for Sydney, we do pay particular attention to this measure of heat stress but use AT and humidex to ensure conclusions are not dependent on any one measure.

\section{1) SWBGT}

SWBGT is a simplified measure of heat stress that considers the ambient air temperature and humidity. The SWBGT is defined as

$$
\text { SWBGT }=0.567 T+0.393 \mathrm{VP}+3.94,
$$

where $\mathrm{VP}$ is the vapor pressure $(\mathrm{hPa})$ given by

$$
\mathrm{VP}=\frac{\mathrm{RH}}{100} \times 6.105 \times \exp ^{\frac{172 \times T}{237.7+T}}
$$

where $T$ is the dry bulb temperature $\left({ }^{\circ} \mathrm{C}\right)$ and $\mathrm{RH}$ is relative humidity (\%).

The SWBGT was originally designed by the U.S. military as a measure to prevent heat-related injuries 
during training and is the International Organization for Standardization (ISO) standard for quantifying heat stress (ISO 1989; Parsons 2006). The SWBGT is currently in use by a number of bodies including the U.S. and U.K. military, civil engineers, sports associations (especially Australian), and the Australian Bureau of Meteorology (BoM; Australian Bureau of Meteorology 2016; American College of Sports Medicine 1984; Buzan et al. 2015). It is the only heat index to have known thresholds relating directly to levels of physical activity (Willett and Sherwood 2012) and is popular for global heat stress assessments (Sherwood and Huber 2010; Oleson et al. 2015; Zhao et al. 2015). Note that SWBGT, while widely used, does not take wind speed and radiation into account.

2) $\mathrm{AT}$

Apparent temperature was developed using a combination of wind and heat transfer to measure thermal comfort and thermal responses in humans (Steadman 1994; Buzan et al. 2015):

$$
\mathrm{AT}=T+0.33 \mathrm{VP}-0.7 U_{10 \mathrm{~m}}-4.0
$$

where $U_{10 \mathrm{~m}}$ is the wind velocity $\left(\mathrm{ms}^{-1}\right)$ at $10 \mathrm{~m}$. The metric is an approximation of a prognostic thermal model of human comfort (Buzan et al. 2015; Steadman 1994). It is used by the BoM in Australia as well as in other regions around the world (Australian Bureau of Meteorology 2016; Anderson et al. 2013; Buzan et al. 2015).

\section{3) HuMideX}

Humidex is an index developed for the Meteorological Service of Canada and describes the "feel like" temperature for humans (Masterton and Richardson 1979; Buzan et al. 2015):

$$
\text { humidex }=T+\frac{5}{9}(\mathrm{VP}-10)
$$

\section{Results}

\section{a. Impact on meteorological variables}

The impact of the six mitigation strategies on 2-m ambient air temperature (T2) is shown in Fig. 2a. In results consistent with many previous studies (e.g., Ohashi et al. 2016; Sun et al. 2016), COOL and SD60 cool $\mathrm{T} 2$ by $\sim\left(0.5^{\circ}-1.0^{\circ}\right) \mathrm{C}$ with increased cooling as the density of urbanization increases. In the case of GR, without water supply, both evaporation and transpiration from vegetation are negligible because of low soil moisture. Consequently, GR has little impact on the ambient air temperature. Note that GR does not simulate the dynamics of growing and wilting of plants; rather, it assumes that the vegetation is always alive and evapotranspiration processes are controlled by the soil moisture. On the other hand, irrigated GR makes a dramatic difference, leading to a cooling of around 1.5 times that of COOL or SD60. Irrigated gardens and parks generate cooling but by comparatively little $\left(<0.5^{\circ} \mathrm{C}\right)$.

The COOL, SD60, and GR without irrigation have little impact on atmospheric vapor pressure (VP; a measure of the amount of water in the atmosphere; Fig. 2b), whereas the GR and GD with irrigation increase VP significantly, by $0.1-2.4 \mathrm{hPa}$. A decrease in wind speed (mostly $<1.0 \mathrm{~m} \mathrm{~s}^{-1}$ ) occurs when COOL, SD60, GR+IRI, or GR+GD+IRI is implemented (Fig. 2c).

\section{b. Impact on heat stress metrics}

The impact on SWBGT, AT, and humidex is shown in Figs. 3a, 3b, and 3c. COOL and SD60 have a substantial impact on all three heat stress indices. The magnitude of the decrease in each index increases with the density of urbanization. Decreases reach $\sim 0.7^{\circ} \mathrm{C}$ for COOL and SD60 for SWBGT and AT and are $\sim 1.1^{\circ} \mathrm{C}$ for humidex.

In contrast, the irrigated experiments either show around $0.1^{\circ} \mathrm{C}$ reduction in the heat indices (SWBGT) or an impact of only half of the decreases of AT and humidex found in the COOL and SD60 experiments. The GR simulations without irrigation had a $0.15^{\circ} \mathrm{C}$ impact on the heat indices. Also shown for reference in the online supplemental material are the contributions of $T$ and VP to the change in heat stress metrics (Figs. S2 and S3, respectively).

In short, our simulations demonstrate that while irrigating green roofs $(\mathrm{GR}+\mathrm{IRI})$ and green roofs, parks, and gardens $(\mathrm{GR}+\mathrm{GD}+\mathrm{IRI})$ have a much greater impact on temperature than do COOL and SD60, the addition of irrigation increases the amount of moisture in the air to either fully offset the temperature cooling benefits (SWBGT) or approximately halve the benefits (humidex and AT).

\section{Discussion}

The changes shown in Figs. 2 and 3 can be explained via a combination of the impact of the various mitigation strategies on net radiation (Rnet), latent heat (LH) and sensible heat (SH) fluxes, and heat storage (STH). The different mitigation strategies interact with the surface energy balance through different mechanisms, either by changing the amount of net radiation (a radiative process) or via how the net radiation is partitioned between latent heat and sensible heat (a nonradiative process). The effectiveness of the mitigation options shown in this study and the processes via which they occur are consistent with previous studies including those of Sun et al. (2016), Li et al. (2014), Salamanca et al. (2016), and Sharma et al. (2016). 

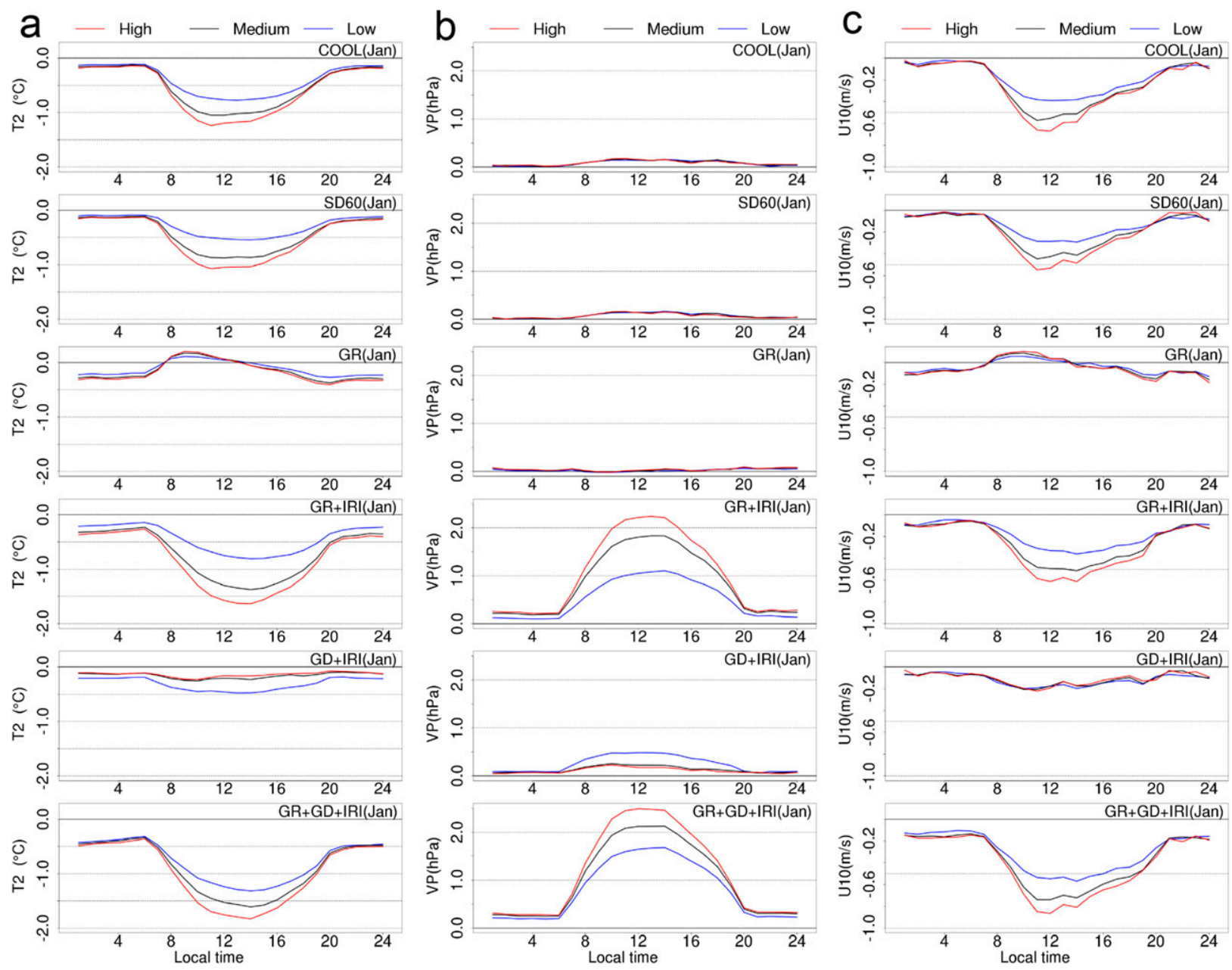

FIG. 2. The effects of mitigation options on T2, VP, and $U_{10 \mathrm{~m}}$ COOL, SD60, GR, GR+IRI, GD+IRI, and GR+GD+IRI are expressed as the difference of the mitigation option experiment and control experiment (see Fig. S1 in the online supplemental material for the diurnal-cycle results of the control experiment).

Cool roofs simply reflect more incoming solar radiation, and hence, less net radiation is available at the surface (Li et al. 2014; Yang et al. 2015b). In our COOL experiment, the reduced absorption of solar radiation leads to a decrease in net radiation of between 100 and $200 \mathrm{~W} \mathrm{~m}^{-2}$ (Fig. 4a). The lower net radiation decreases the energy available for sensible and latent heat exchange and heat storage, but because the roof surfaces are typically dry, the impact of the lower net radiation is principally via a reduction in the sensible heat flux with a small change in daytime heat storage (Fig. 4a). Figure 4a shows that urban surfaces using cool roofs absorb less energy in the morning hours and hence release less heat at night. The lower atmosphere receives a reduced sensible heat flux, but since there is no change in the latent heat, vapor pressure is changed negligibly (Fig. 2b). Hence, Figs. 2a and 2b show the impact of
COOL to be cooling in temperature with little impact on vapor pressure.

The impact of a deployment of solar panels over roofs is also via radiative forcing, which cools air temperature as solar panels absorb radiation and covert it to electricity (Masson et al. 2014; Salamanca et al. 2016; Taha 2013). In our SD60 experiment (Fig. 4b), the reduction in the sensible heat is caused by the net radiation being removed from the surface energy balance to generate electricity and thereby reduce the energy available for sensible heat. In summary, the cooling found for COOL and SD60 is principally driven by the removal of energy from the surface energy balance either by reflection (COOL) or through use in energy production (SD60). In both cases, less net radiation is available, which leads directly to the reduction of sensible heat and thereby the magnitude of warming of the lower atmosphere. 

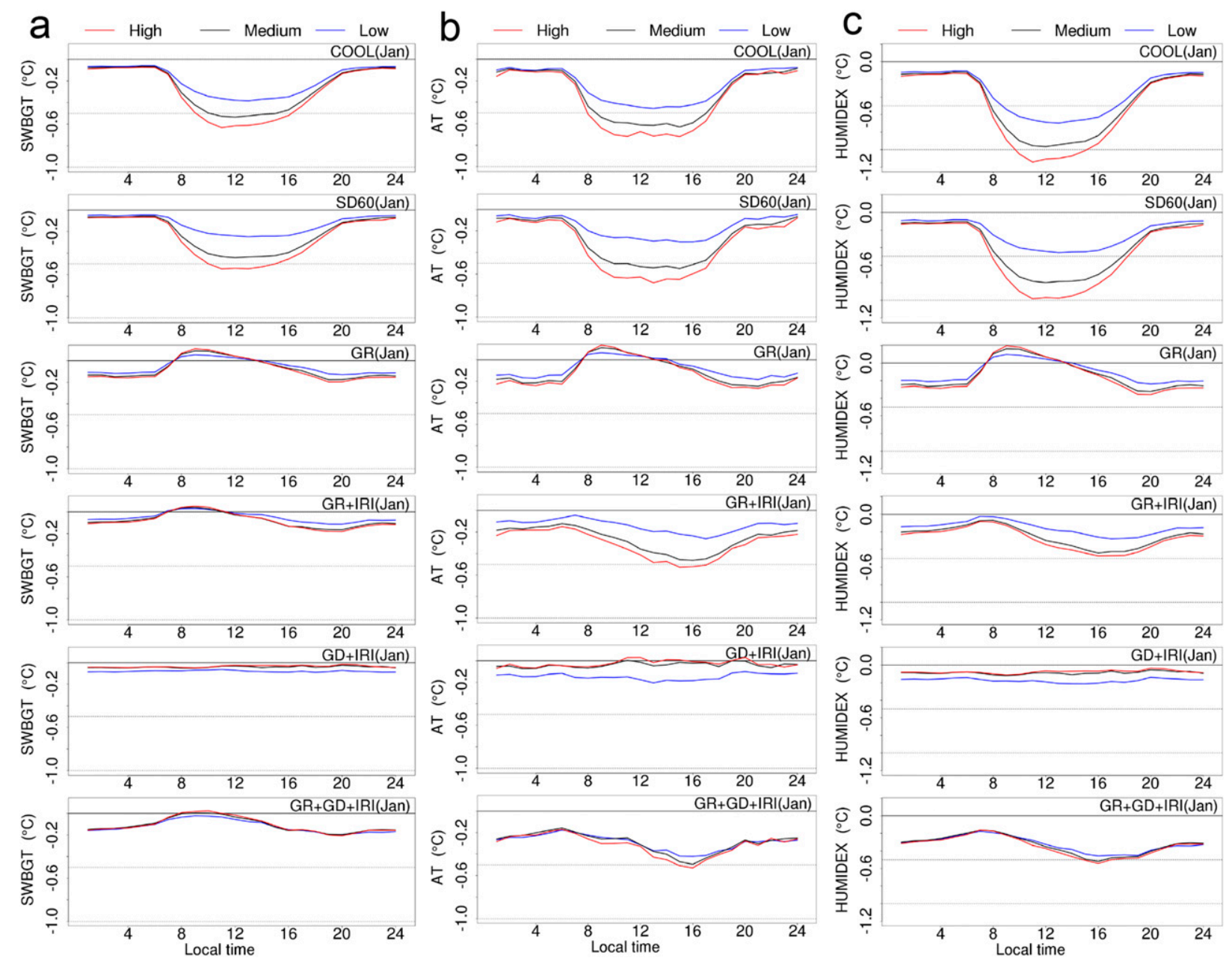

FIG. 3. As in Fig. 2, but on the heat stress metrics SWBGT, AT, and humidex.

The impact of a deployment of green roofs occurs via a nonradiative pathway, which leads to cooler air temperatures (Sun et al. 2016; Vijayaraghavan 2016). For GR, the impact on albedo and thereby net radiation is very small (Fig. 4c). While the different heat capacity and thermal properties of the green roof result in small changes in heat storage (Fig. 4c), this had minor impacts on the diurnal distribution of sensible heat fluxes. Note that there is little precipitation during these summer months and the GR soil profile remains quite dry throughout the simulations. This suggests that the effects of GR are negligible during dry periods and irrigation is necessary to realize significant benefits. We note that a benefit of COOL in comparison with GR is that the additional water is not required, which is particularly advantageous during hot and dry periods.

Irrigation profoundly changes the partitioning of net radiation between latent heat and sensible heat (Tsilini et al. 2015; Van Mechelen et al. 2015; Yang and Wang
2015). Under the GR+IRI scenario, there is a small impact on net radiation but a large increase in latent heat (Figs. 4d and 4f), because water is available to support evaporation. Given the change in net radiation is small, a large increase in latent heat must be compensated by a decrease in the sensible heat flux. This is particularly clear in GR + IRI (Fig. 4d) and GR+GD+IRI (Fig. 4f). As a consequence, the surface is cooled by evaporation (Fig. 2a) at the expense of the sensible heat flux, and the atmosphere is consequently cooled and moistened. Figure 2a therefore shows cooling, and Fig. 2b shows an increase in atmospheric vapor pressure. In summary, the cooling in GR+IRI and GR+GD+IRI is principally driven by a repartitioning of net radiation from a sensible heat- to a latent heat-driven surface energy balance.

The reduction of wind speed is related to the cooling effects of different mitigation options (Figs. 2a and 2c). This is mainly due to the cooler urban environment weakening the penetration of wind from rural areas. 

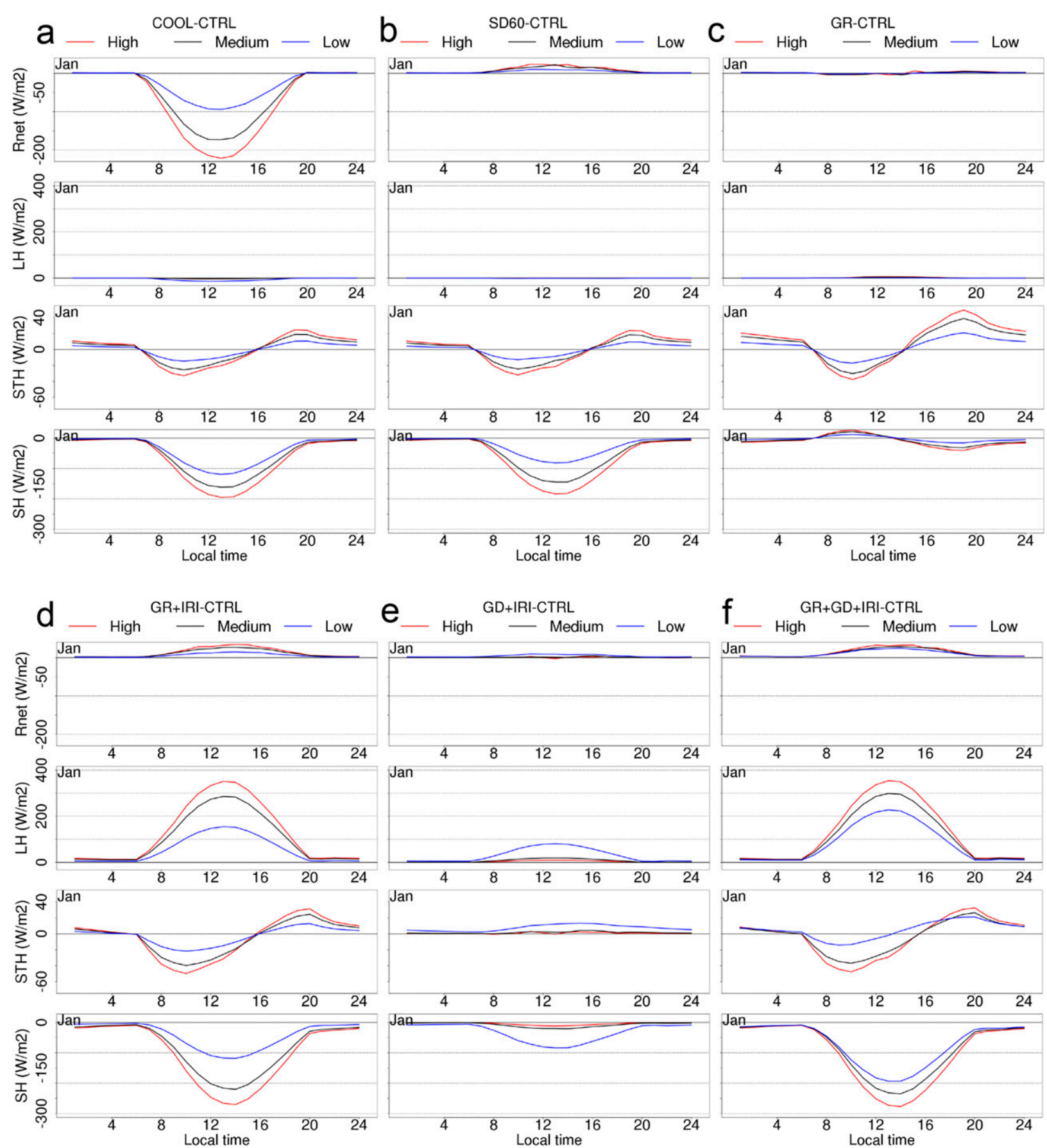

FIG. 4. As in Fig. 2, but on the surface energy balance components Rnet, LH, STH, and SH. Positive heat storage indicates that the ground receives energy from the atmosphere.

This, in turn, is associated with the establishment of urban-rural thermal contrasts that can drive circulation patterns (Lemonsu et al. 2006). Under the conditions simulated here, the winds in Sydney are most commonly from the ocean toward the urban areas because of the strong thermal contrast between the warm land and the cooler ocean. Our results show a decrease of the ambient air temperature over urban areas, particularly during the day. This cooling weakens the thermal landocean contrast and thereby tends to decrease wind speeds. Our results here are consistent with those found by Sun et al. (2016), who also found a reduction of wind speed $\left(\sim 1.0 \mathrm{~m} \mathrm{~s}^{-1}\right)$ due to the deployment of green roofs in a modeling study focused on Beijing, China. 
The limited effectiveness of green roofs with sufficient water in reducing heat stress was noted by previous studies that highlighted the negative impact of an increase in humidity on the benefits of cooling ambient air temperature of green roofs (Ohashi et al. 2016; Sun et al. 2016). Ohashi et al. (2016) reported that the deployment of green roof did not reduce SWBGT and heat risk in Tokyo, Japan. Sun et al. (2016) found that a green roof lowered the air ambient temperature by $2.5^{\circ} \mathrm{C}$ but only reduced the apparent temperature by $\sim 1.7^{\circ} \mathrm{C}$ in Beijing. Building on previous studies, we examined the effectiveness of green roofs with sufficient water or with a dry soil on heat stress using three widely used heat stress metrics in Australia. In this study, the green roofs without sufficient water experiment shows a reduction of $\sim 0.2^{\circ} \mathrm{C}$ in the heat indices (Fig. 3a), while the green roofs with sufficient water experiment shows the larger decrease of AT $\left(\sim 0.5^{\circ} \mathrm{C}\right)$. This is about $35 \%$ of the reduction of ambient air temperature $\left(\sim 1.6^{\circ} \mathrm{C}\right.$; Fig. $\left.2 \mathrm{a}\right)$. This highlighted the limitation of green roofs as a mitigation strategy because the increase in humidity counteracts the benefits obtained from cooling. In addition, the cooling effects of COOL and SD60 experiment take place coincident with the hottest time period of day (around 1300 LST), but irrigation experiments predict the maximum reduction in the late afternoon and during the night. This highlighted the advantage of the cooling effects of SD60 and COOL experiment relative to the green roof with irrigation in the context of heat stress. We also note the considerable investment required for green roofs and the costs associated with water. This suggests that in areas vulnerable to extreme heat, which are most commonly also likely to be dry, green roofs with irrigation may not be a widely applicable mitigation strategy. In contrast, our COOL and SD60 experiments show that the deployment of cool roofs and solar panels can reduce ambient air temperature without increasing humidity, which leads to a positive overall outcome on heat stress indices. Of course, the deployment of solar panels can generate electricity (Ma et al. 2017a) and help offset installation costs. Overall, our study helps confirm concerns about green roofs raised by previous studies (Ohashi et al. 2016; Sun et al. 2016) but also proposed alternative mitigation strategies that avoid some of the challenges with green roofs.

Previous studies tended to focus on a single heat stress index (Fischer et al. 2012; Ohashi et al. 2016; Sherwood and Huber 2010; Sun et al. 2016; Willett and Sherwood 2012). A few previous studies compared two metrics (Oleson et al. 2015; Buzan et al. 2015), with Oleson et al. (2015) noting the dependency of conclusions on the index used and Budd (2008), D'Ambrosio Alfano et al. (2012), and Davies-Jones (2008) all criticizing the inaccuracy of specific heat stress metrics. The lack of any single agreed heat stress index has led to comparisons of indices (Buzan et al. 2015). We do not attempt to determine the best way of measuring heat stress here; rather, we examined how robust conclusions were to the use of three widely used heat stress metrics. Irrespective of the metric used, our results point to the limited effectiveness of green roofs in reducing heat stress as compared with that of the deployment of solar panel or cool roofs. We note that one of the metrics, SWBGT, is widely used in Australia, and our results point to its utility in assessing heat stress in ways consistent with alternative methods.

It is worth noting that the model accounts for the contribution from rooftops when estimating temperature and humidity at $2 \mathrm{~m}$ inside the canyon, whereas, in reality, rooftop infrastructures, far above the street level, may have limited effects on the thermal comfort of pedestrians. WRF tends to overestimate the impact of green and cool roofs, and to achieve the predicted benefits in this study would need air over rooftop to be mixed down to street level to impact the population. We also do not differentiate tree canopy from grasses. Trees have the potential benefit of shading the street level, where people are, and emitting (most of) the extra water vapor above the canopy. This, like green roofs, would need to be mixed down to the surface in order to impact people. Further study is required to understand the impact of these factors on heat stress at street level.

The focus of the current study is the effects of mitigation strategies on heat stress mitigation. Of course, there would be other benefits and disadvantages of the mitigation strategies examined here. The installment of solar panels over roofs could reduce temperature but also generate an important source of energy in the future (Ma et al. 2017a). More targeted field and numerical studies are necessary to examine fully the benefits of the different mitigation strategies. An integrated assessment study, including the effects on health, economy, comfort, and environment, would be worthwhile.

\section{Conclusions}

Human thermal comfort, and any associated heat stress, is determined by a combination of temperature, humidity, wind, and radiation. A mitigation strategy that cools the atmosphere might be expected to improve human comfort. However, if that strategy also increases atmospheric moisture, benefits resulting from cooling can be negated by increasing humidity, at least during summer in Sydney. We suspect our results would apply to other cities although a more generalizable understanding of how climate, urban form, and summer heat and humidity combine to affect a population would be worth developing. 
In our experiments, COOL and SD60 benefit human thermal comfort by cooling the urban ambient environment. They achieve this cooling by a direct reduction in net radiation via reflection of incoming solar radiation (COOL) or by using the incident energy for electricity production (SD60), thereby reducing sensible heat, which would otherwise have heated the atmosphere. In contrast, those methods that cool the surface via evaporation through the use of irrigation did cool the atmosphere, commonly by more than COOL and SD60, but, by increasing the amount of water in the air, their net impact on human comfort was negligible or at most half that of COOL and SD60.

Cooling a city has been proposed as a strategy to improve the health and well-being of its inhabitants. However, cooling via evaporative methods risks a counterintuitive effect of decreasing human comfort. Cooling via white or light-colored roofs has a direct impact on temperature. SD60 has a similar impact on temperature but has the added benefit of generating electricity, which could, at least to some degree, offset the cost of their installation.

Acknowledgments. We acknowledge the support of the Australian Research Council via the Centre of Excellence for Climate System Science (CE110001028). Supercomputing time was provided by the National Computational Infrastructure Facility.

\section{REFERENCES}

American College of Sports Medicine, 1984: Prevention of thermal injuries during distance running: Position stand. Med. J. Aust., 141, 876-879.

Anderson, G. B., M. L. Bell, and R. D. Peng, 2013: Methods to calculate the heat index as an exposure metric in environmental health research. Environ. Health Perspect., 121, 11111119, https://doi.org/10.1289/ehp.1206273.

Argüeso, D., J. P. Evans, L. Fita, and K. J. Bormann, 2014: Temperature response to future urbanization and climate change. Climate Dyn., 42, 2183-2199, https://doi.org/10.1007/ s00382-013-1789-6.

,,-- A. J. Pitman, and A. Di Luca, 2015: Effects of city expansion on heat stress under climate change conditions. PLoS One, 10, e0117066, https://doi.org/10.1371/journal.pone.0117066.

Australian Bureau of Meteorology, 2016: Thermal comfort observations. Australian Bureau of Meteorology, accessed 2 December 2016, http://www.bom.gov.au/info/ thermal_stress/.

_ 2017: Climate statistics for Australian locations. Australian Bureau of Meteorology, http://www.bom.gov.au/climate/ averages/tables/cw_066062_All.shtml.

Barnett, A. G., 2007: Temperature and cardiovascular deaths in the US elderly: Changes over time. Epidemiology, 18, 369-372, https://doi.org/10.1097/01.ede.0000257515.34445.a0.

Budd, G. M., 2008: Wet-bulb globe temperature (WBGT)-Its history and its limitations. J. Sci. Med. Sport, 11, 20-32, https:// doi.org/10.1016/j.jsams.2007.07.003.
Buzan, J. R., K. Oleson, and M. Huber, 2015: Implementation and comparison of a suite of heat stress metrics within the Community Land Model version 4.5. Geosci. Model Dev., 8, 151170, https://doi.org/10.5194/gmd-8-151-2015.

Carson, C., S. Hajat, B. Armstrong, and P. Wilkinson, 2006: Declining vulnerability to temperature-related mortality in London over the 20th century. Amer. J. Epidemiol., 164, 77-84, https://doi.org/10.1093/aje/kwj147.

Chen, F., and Coauthors, 2011: The integrated WRF/urban modelling system: Development, evaluation, and applications to urban environmental problems. Int. J. Climatol., 31, 273-288, https://doi.org/10.1002/joc.2158.

D’Ambrosio Alfano, F. R., B. I. Palella, and G. Riccio, 2012: On the problems related to natural wet bulb temperature indirect evaluation for the assessment of hot thermal environments by means of WBGT. Ann. Occup. Hyg., 56, 1063-1079, https:// doi.org/10.1093/annhyg/mes036.

Davies-Jones, R., 2008: An efficient and accurate method for computing the wet-bulb temperature along pseudoadiabats. Mon. Wea. Rev., 136, 2764-2785, https://doi.org/10.1175/ 2007MWR2224.1.

Davis, R. E., P. C. Knappenberger, P. J. Michaels, and W. M. Novicoff, 2003: Changing heat-related mortality in the United States. Environ. Health Perspect., 111, 1712-1718, https://doi.org/10.1289/ehp.6336.

Dee, D. P., and Coauthors, 2011: The ERA-Interim reanalysis: Configuration and performance of the data assimilation system. Quart. J. Roy. Meteor. Soc., 137, 553-597, https://doi.org/ 10.1002/qj.828.

Dunne, J. P., R. J. Stouffer, and J. G. John, 2013: Reductions in labour capacity from heat stress under climate warming. Nat. Climate Change, 3, 563-566, https://doi.org/10.1038/nclimate1827.

Evans, J. P., F. Ji, C. Lee, P. Smith, D. Argüeso, and L. Fita, 2014: Design of a regional climate modelling projection ensemble experiment-NARCliM. Geosci. Model Dev., 7, 621-629, https://doi.org/10.5194/gmd-7-621-2014.

Fischer, E. M., K. W. Oleson, and D. M. Lawrence, 2012: Contrasting urban and rural heat stress responses to climate change. Geophys. Res. Lett., 39, L03705, https://doi.org/ 10.1029/2011GL050576.

Georgescu, M., P. E. Morefield, B. G. Bierwagen, and C. P. Weaver, 2014: Urban adaptation can roll back warming of emerging megapolitan regions. Proc. Natl. Acad. Sci. USA, 111, 2909-2914, https://doi.org/10.1073/pnas.1322280111.

Green, M. A., K. Emery, Y. Hishikawa, W. Warta, and E. D. Dunlop, 2016: Solar cell efficiency tables (version 47). Prog. Photovoltaics Res. Appl., 24, 3-11, https://doi.org/10.1002/pip.2728.

Guo, Y., and Coauthors, 2016: Temperature variability and mortality: A multi-country study. Environ. Health Perspect., 124, 1554-1559, https://doi.org/10.1289/EHP149.

Hass, A. L., K. N. Ellis, L. Reyes Mason, J. M. Hathaway, and D. A. Howe, 2016: Heat and humidity in the city: Neighborhood heat index variability in a mid-sized city in the southeastern United States. Int. J. Environ. Res. Public Health, 13, 117, https://doi.org/10.3390/ijerph13010117.

$\mathrm{Hu}$, A., and Coauthors, 2016: Impact of solar panels on global climate. Nat. Climate Change, 6, 290-294, https://doi.org/ 10.1038/nclimate2843.

ISO, 1989: Hot environments-Estimation of the heat stress on working man, based on the WBGT-index (wet bulb globe temperature). 2nd ed. International Organization for Standardization Rep. ISO 7243:1989, 9 pp., http://www.iso.org/iso/ catalogue_detail.htm?csnumber $=13895$. 
Jackson, T. L., J. J. Feddema, K. W. Oleson, G. B. Bonan, and J. T. Bauer, 2010: Parameterization of urban characteristics for global climate modeling. Ann. Assoc. Amer. Geogr., 100, 848-865, https://doi.org/10.1080/ 00045608.2010 .497328 .

Kusaka, H., and F. Kimura, 2004: Thermal effects of urban canyon structure on the nocturnal heat island: Numerical experiment using a mesoscale model coupled with an urban canopy model. J. Appl. Meteor., 43, 1899-1910, https://doi.org/10.1175/ JAM2169.1.

—_, H. Kondo, Y. Kikegawa, and F. Kimura, 2001: A simple single-layer urban canopy model for atmospheric models: Comparison with multi-layer and slab models. Bound.Layer Meteor., 101, 329-358, https://doi.org/10.1023/ A:1019207923078.

Lemonsu, A., G. Pigeon, V. Masson, and C. Moppert, 2006: Sea-town interactions over Marseille: 3D urban boundary layer and thermodynamic fields near the surface. Theor. Appl. Climatol., 84, 171-178, https://doi.org/10.1007/ s00704-005-0155-y.

Li, D., E. Bou-Zeid, and M. Oppenheimer, 2014: The effectiveness of cool and green roofs as urban heat island mitigation strategies. Environ. Res. Lett., 9, 055002, https://doi.org/10.1088/ 1748-9326/9/5/055002

Ma, S., M. Goldstein, A. J. Pitman, N. Haghdadi, and I. MacGill, 2017a: Pricing the urban cooling benefits of solar panel deployment in Sydney, Australia. Sci. Rep., 7, 43938, https:// doi.org/10.1038/srep43938.

_ , A. Pitman, M. Hart, J. P. Evans, N. Haghdadi, and I. MacGill, 2017b: The impact of an urban canopy and anthropogenic heat fluxes on Sydney's climate. Int. J. Climatol., 37, 255-270, https://doi.org/10.1002/joc.5001.

Masson, V., M. Bonhomme, J.-L. Salagnac, X. Briottet, and A. Lemonsu, 2014: Solar panels reduce both global warming and urban heat island. Front. Environ. Sci., 2, 14, https:// doi.org/10.3389/fenvs.2014.00014.

Masterton, J. M., and F. A. Richardson, 1979: Humidex: A method of quantifying human discomfort due to excessive heat and humidity. Environment Canada Rep., 45 pp.

Miao, S., and F. Chen, 2014: Enhanced modeling of latent heat flux from urban surfaces in the Noah/single-layer urban canopy coupled model. Sci. China Earth Sci., 57, 2408-2416, https:// doi.org/10.1007/s11430-014-4829-0.

Ohashi, Y., T. Ihara, Y. Kikegawa, and N. Sugiyama, 2016: Numerical simulations of influence of heat island countermeasures on outdoor human heat stress in the 23 wards of Tokyo, Japan. Energy Build., 114, 104-111, https://doi.org/10.1016/ j.enbuild.2015.06.027.

Oleson, K. W., G. B. Bonan, and J. Feddema, 2010: Effects of white roofs on urban temperature in a global climate model. Geophys. Res. Lett., 37, L03701, https://doi.org/10.1029/ 2009GL042194.

—_, A. Monaghan, O. Wilhelmi, M. Barlage, N. Brunsell, J. Feddema, L. Hu, and D. F. Steinhoff, 2015: Interactions between urbanization, heat stress, and climate change. Climatic Change, 129, 525-541, https://doi.org/10.1007/ s10584-013-0936-8.

Parsons, K., 2006: Heat stress standard ISO 7243 and its global application. Ind. Health, 44, 368-379, https://doi.org/10.2486/ indhealth.44.368.

Salamanca, F., M. Georgescu, A. Mahalov, M. Moustaoui, and A. Martilli, 2016: Citywide impacts of cool roof and rooftop solar photovoltaic deployment on near-surface air tempera- ture and cooling energy demand. Bound.-Layer Meteor., 161, 203-221, https://doi.org/10.1007/s10546-016-0160-y.

Sharma, A., P. Conry, H. J. S. Fernando, A. F. Hamlet, J. J. Hellmann, and F. Chen, 2016: Green and cool roofs to mitigate urban heat island effects in the Chicago metropolitan area: Evaluation with a regional climate model. Environ. Res. Lett., 11, 064004, https://doi.org/10.1088/1748-9326/11/6/ 064004.

Sheridan, S. C., A. J. Kalkstein, and L. S. Kalkstein, 2009: Trends in heat-related mortality in the United States, 19752004. Nat. Hazards, 50, 145-160, https://doi.org/10.1007/ s11069-008-9327-2.

Sherwood, S. C., and M. Huber, 2010: An adaptability limit to climate change due to heat stress. Proc. Natl. Acad. Sci. USA, 107, 9552-9555, https://doi.org/10.1073/ pnas.0913352107.

Shi, L., I. Kloog, A. Zanobetti, P. Liu, and J. D. Schwartz, 2015: Impacts of temperature and its variability on mortality in New England. Nat. Climate Change, 5, 988-991, https://doi.org/ 10.1038/nclimate2704.

Skamarock, W. C., and Coauthors, 2008: A description of the Advanced Research WRF version 3. NCAR Tech. Note NCAR/TN-475+STR, 113 pp., http://dx.doi.org/10.5065/ D68S4MVH.

Steadman, R. G., 1994: Norms of apparent temperature in Australia. Aust. Meteor. Mag., 43, 1-16.

Sun, T., C. S. B. Grimmond, and G.-H. Ni, 2016: How do green roofs mitigate urban thermal stress under heat waves? J. Geophys. Res. Atmos., 121, 5320-5335, https://doi.org/ 10.1002/2016JD024873.

Taha, H., 2013: The potential for air-temperature impact from large-scale deployment of solar photovoltaic arrays in urban areas. Sol. Energy, 91, 358-367, https://doi.org/10.1016/ j.solener.2012.09.014.

Tsilini, V., S. Papantoniou, D.-D. Kolokotsa, and E.-A. Maria, 2015: Urban gardens as a solution to energy poverty and urban heat island. Sustainable Cities Soc., 14, 323-333, https://doi.org/10.1016/j.scs.2014.08.006.

Van Mechelen, C., T. Dutoit, and M. Hermy, 2015: Adapting green roof irrigation practices for a sustainable future: A review. Sustainable Cities Soc., 19, 74-90, https://doi.org/ 10.1016/j.scs.2015.07.007.

Vijayaraghavan, K., 2016: Green roofs: A critical review on the role of components, benefits, limitations and trends. Renewable Sustainable Energy Rev., 57, 740-752, https://doi.org/ 10.1016/j.rser.2015.12.119.

Willett, K. M., and S. Sherwood, 2012: Exceedance of heat index thresholds for 15 regions under a warming climate using the wet-bulb globe temperature. Int. J. Climatol., 32, 161-177, https://doi.org/10.1002/joc.2257.

Yang, J., and Z.-H. Wang, 2014: Physical parameterization and sensitivity of urban hydrological models: Application to green roof systems. Build. Environ., 75, 250-263, https://doi.org/ 10.1016/j.buildenv.2014.02.006.

, and —, 2015: Optimizing urban irrigation schemes for the trade-off between energy and water consumption. Energy Build., 107, 335-344, https://doi.org/10.1016/ j.enbuild.2015.08.045.

, — - F. Chen, S. Miao, M. Tewari, J. A. Voogt, and S. Myint, 2015a: Enhancing hydrologic modelling in the coupled Weather Research and Forecasting-urban modelling system. Bound.-Layer Meteor., 155, 87-109, https://doi.org/10.1007/ s10546-014-9991-6. 
and K. E. Kaloush, 2015b: Environmental impacts of reflective materials: Is high albedo a "silver bullet" for mitigating urban heat island? Renewable Sustainable Energy Rev., 47, 830-843, https://doi.org/10.1016/j.rser.2015.03.092.

,,- M. Georgescu, F. Chen, and M. Tewari, 2016: Assessing the impact of enhanced hydrological processes on urban hydrometeorology with application to two cities in contrasting climates. J. Hydrometeor., 17, 1031-1047, https://doi.org/ 10.1175/JHM-D-15-0112.1.
Zander, K. K., W. J. W. Botzen, E. Oppermann, T. Kjellstrom, and S. T. Garnett, 2015: Heat stress causes substantial labour productivity loss in Australia. Nat. Climate Change, 5, 647651, https://doi.org/10.1038/nclimate2623.

Zhao, Y., A. Ducharne, B. Sultan, P. Braconnot, and R. Vautard, 2015: Estimating heat stress from climate-based indicators: Present-day biases and future spreads in the CMIP5 global climate model ensemble. Environ. Res. Lett., 10, 084013, https://doi.org/10.1088/1748-9326/10/8/084013. 